\title{
A Library of Large-eddy Simulations for Calibrating Cloud Parameterizations
}

Zhaoyi Shen ${ }^{1}$, Akshay Sridhar ${ }^{1}$, Zhihong Tan $^{2}$, Anna Jaruga $^{1}$, Tapio Schneider ${ }^{1,3}$

\author{
${ }^{1}$ Department of Environmental Science and Engineering, California Institute of Technology, Pasadena, \\ CA, USA \\ ${ }^{2}$ Program in Atmospheric and Oceanic Science, Princeton University, Princeton, NJ, USA \\ 3 Jet Propulsion Laboratory, Pasadena, CA, USA
}

Key Points:

- A library of high-resolution simulations of clouds is created using LES driven by a GCM.

- The LES library can be used to train parameterizations in a GCM and to investigate cloud feedbacks.

Corresponding author: Zhaoyi Shen, zhaoyi@caltech.edu 




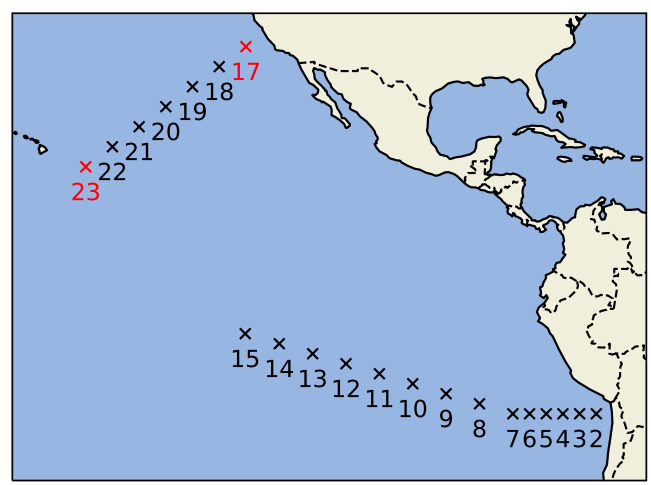

Figure 1: cfSites locations used in this study. The sites cover the transition from stratocumulus to shallow cumulus over the East Pacific. The red crosses highlight site 17 and site 23, two locations on which we focus in the paper. They represent cloud regimes of stratocumulus and shallow cumulus, respectively.

\subsection{Forcing Framework}

The forcing framework is similar to that in Shen et al. (2020). Here we briefly summarize the large-scale forcings in the LES and describe the difference to Shen et al. (2020).

\subsubsection{Subsidence}

Large-scale subsidence gives rise to a source in the specific entropy $(s)$ and specific humidity $\left(q_{t}\right)$ equations:

$$
\begin{aligned}
\frac{d s}{d t} & =-\langle\tilde{w}\rangle \frac{\partial s}{\partial z}, \\
\frac{d q_{t}}{d t} & =-\langle\tilde{w}\rangle \frac{\partial q_{t}}{\partial z} .
\end{aligned}
$$

Here, $w=d z / d t$ is the vertical velocity, $(\tilde{\cdot})$ denotes a GCM value, and $\langle\cdot\rangle$ denotes the time mean. The time-averaged vertical velocity is approximated by $\langle\tilde{w}\rangle \approx-\langle\tilde{\omega}\rangle\langle\tilde{\alpha}\rangle / g$, where we have ignored small terms associated with the horizontal advection of pressure and assumed that the pressure-coordinate vertical velocity $\tilde{\omega}$ and the specific volume $\tilde{\alpha}$ are uncorrelated.

\subsubsection{Advection} GCM as

Horizontal advection and vertical eddy advection are prescribed directly from the

$$
\begin{gathered}
\frac{d s}{d t}=\frac{c_{p}}{T}\left(\left\langle J_{\text {hadv }}\right\rangle+\left\langle J_{\text {veddy }}\right\rangle\right)+\left(s_{v}-s_{d}\right)\left(\left\langle S_{\text {hadv }}\right\rangle+\left\langle S_{\text {veddy }}\right\rangle\right), \\
\frac{d q_{t}}{d t}=\left\langle S_{\text {hadv }}\right\rangle+\left\langle S_{\text {veddy }}\right\rangle,
\end{gathered}
$$

where $c_{p}$ is the isobaric specific heat capacity of air; $T$ is temperature; and $s_{d}$ and $s_{v}$ are specific entropies of dry air and water vapor, respectively. The terms $S_{\text {hadv }}$ and $J_{\text {hadv }}$ represent horizontal advection of specific humidity and temperature, and $S_{\text {veddy }}$ and $J_{\text {veddy }}$ represent vertical eddy advection of specific humidity and temperature. All four advection terms are derived from the GCM. The cfsites output includes total advective ten- 
dencies of specific humidity $\left(S_{\text {adv }}\right)$ and temperature $\left(J_{\text {adv }}\right)$. We obtain the horizontal advective tendencies from the total advective tendencies as the residuals

$$
S_{\mathrm{hadv}}=S_{\mathrm{adv}}+\tilde{w} \frac{\partial \tilde{q}_{t}}{\partial z},
$$

and

$$
J_{\mathrm{hadv}}=J_{\mathrm{adv}}+\tilde{w} \frac{\partial \tilde{T}}{\partial z}+\tilde{w} \frac{g}{c_{p}} .
$$

The vertical eddy advective tendencies are derived as

$$
S_{\text {veddy }}=-\left\langle\tilde{w} \frac{\partial \tilde{q}_{t}}{\partial z}\right\rangle+\langle\tilde{w}\rangle \frac{\partial\left\langle\tilde{q}_{t}\right\rangle}{\partial z},
$$

and

$$
J_{\text {veddy }}=-\left\langle\tilde{w} \frac{\partial T}{\partial z}\right\rangle+\langle\tilde{w}\rangle \frac{\partial\langle\tilde{T}\rangle}{\partial z} .
$$

\subsubsection{Relaxation}

Unlike in Shen et al. (2020), the large-scale momentum forcing is not applied. Instead, the horizontal winds are relaxed to the GCM profiles on a timescale of $6 \mathrm{~h}$. Freetropospheric temperatures $T$ and humidities $q_{t}$ are relaxed to GCM profiles to prevent drifting from realistic conditions. The relaxation timescale varies with height as

$$
\Gamma_{r}(z)=\frac{1}{\tau_{r}} \times \begin{cases}0 & z<z_{i} \\ 0.5\left(1-\cos \left(\pi \frac{z-z_{i}}{z_{r}-z_{i}}\right)\right) & z_{i} \leq z \leq z_{r} \\ 1 & z>z_{r}\end{cases}
$$

Relaxation forcing is commonly used when driving LES or single column models with GCMs or reanalysis, and the timescale is usually a few hours (e.g. Randall \& Cripe, 1999; Neggers et al., 2012; Zhang et al., 2012). In this study, we set $\tau_{r}=24 \mathrm{~h}$, and $z_{r}=3500 \mathrm{~m}$ and $z_{i}=3000 \mathrm{~m}$.

\section{Results}

\subsection{LES simulated low clouds}

Figure 2 shows the cloud cover, cloud liquid water path (LWP), cloud base and cloud top at different sites in the LES driven by HadGEM2-A. The LES sample a wide range of cloud regimes. Near the coasts of Peru (sites 2-4) and California (sites 17-18), the simulations produce stratocumulus with cloud cover near $100 \%$. The cloud cover decreases rapidly when moving away from the coast and is about $20-30 \%$ in shallow cumulus regions over the open ocean. The transition from stratocumulus to shallow cumulus is also seen in the decrease in LWP and the increase in cloud top height from the coast to the open ocean.

The cloud properties at different locations have distinct seasonal variations. In the stratocumulus regions off the coasts, cloud cover and LWP are higher in July and October in both hemispheres. In the shallow cumulus regions over the Southeast Pacific, cloud cover and LWP peak in July and show low values in January and April. The cloud base is highest in July and lowest in January, while the cloud top is generally higher in January than in July, suggesting some seasonal variation in the thickness of clouds. In the shallow cumulus regions over the Northeast Pacific, cloud cover and LWP show high values in April and low values in July. The cloud base is highest in April and lowest in July, and the seasonal variation in the cloud top generally follows that in the cloud base height. 
The cloud properties in the LES driven by CNRM-CM5 are shown in Figure 3. Unlike the LES driven by HadGEM2-A, this LES does not simulate a stratus cloud layer near the coast of Peru. In the shallow cumulus regions, the cloud fraction and LWP in some seasons are higher than that in the LES driven by HadGEM2-A, which largely results from differences at the cloud top. The differences between the two host GCMs will be discussed further in Section 3.2.

Figures 4 and 5 show the vertical profiles of large-scale forcings and cloud properties of two sites over the Northeast Pacific in HadGEM2-A in July, representing the cloud regimes of stratocumulus (site 17) and shallow cumulus (site 23). The large-scale subsidence is stronger at site 17 than at site 23 . There is horizontal advective cooling and drying in the boundary layer at both sites, and their tendencies are stronger at site 17. The advective tendencies are consistent with the lower-level winds, which are northerly near the coast (site 17) and northeasterly away from the coast (site 23).

Figure 6 shows the timeseries of cloud cover and LWP at sites 17 and 23. The LES reach quasi-steady states in 1-2 days at both sites, although the relatively small domain size leads to high-frequency oscillations especially for shallow cumulus. The LES simulate stratocumulus under strong subsidence and advective cooling and drying at site 17, with a cloud top at around $1000 \mathrm{~m}$ and a cloud fraction close to 100\% (Figure 4g). The stratocumulus layer is slightly decoupled from the subcloud mixed layer, as seen in the vertical profiles of total water specific humidity, liquid potential temperature, and vertical velocity variance below the inversion (Figures $4 \mathrm{~d}-4 \mathrm{f}$ ). This decoupling may be due to the strong advective cooling at the bottom of the cloud layer (Figure 4b). At site 23 , the LES simulates a shallow cumulus layer with a cloud base at around $500 \mathrm{~m}$ and a cloud top at around $1600 \mathrm{~m}$. The cloud fraction and the corresponding vertical velocity variance have two peaks (Figures $5 \mathrm{~d}$ and $5 \mathrm{~h}$ ): just above the lifted condensation level and just below the inversion. The anvil resulting from the detrainment of cumulus updrafts is ubiquitous in the LES simulations of shallow cumulus sites.

\subsection{Comparison to GCM and sensitivity to large-scale forcing}

We compare the LES-simulated cloud profiles with those in the host GCM, HadGEM2A (Figures $4 \mathrm{~g}, 4 \mathrm{~h}, 5 \mathrm{~g}$, and $5 \mathrm{~h}$ ). At site $17 \mathrm{in} \mathrm{July,} \mathrm{the} \mathrm{GCM} \mathrm{produces} \mathrm{a} \mathrm{lower} \mathrm{but} \mathrm{deeper}$ stratocumulus layer. The cloud base in the GCM is very close to the surface and lower than that in the LES by about $400 \mathrm{~m}$, while the cloud top heights are similar between the GCM and the LES. The maximum cloud fraction and cloud liquid water in the GCM are much smaller than in the LES, and LWP in the GCM is about $40 \%$ smaller. At site 23 , the GCM produces a higher and deeper shallow cumulus layer. The cloud base in the GCM is slightly lower than in the LES, while the cloud top in the GCM is about $500 \mathrm{~m}$ higher. The cloud fraction and cloud liquid water in the GCM are much larger. The GCM only produces one peak in cloud fraction in the middle of the shallow cumulus layer, as opposed to the two peaks at the bottom and the top of the cloud layer in the LES.

Figure 7a compares LWP at all sites simulated by HadGEM2-A and LES. The spread of LWP at different sites is much smaller in the LES than in the GCM, and there is no correlation between the LES and the GCM. In the shallow cumulus regions, LWP is systematically larger in the GCM, mostly resulting from a deeper cloud layer. The difference can be as large as $60 \mathrm{~g} \mathrm{~m}^{-2}$ at several sites (e.g., over the North Pacific). In the stratocumulus regions, the LWP differences between the GCM and the LES are smaller, although the maximum cloud fraction in the stratocumulus layer in the GCM is always much smaller than in the LES. This is because the cloud layer is usually much thicker in the GCM (e.g., Figures $4 \mathrm{~g}$ and $4 \mathrm{~h}$ ).

The large-scale forcing used to drive the LES is dependent on the host GCM. Figure 8 shows the vertical profiles of large-scale forcings and cloud properties in the LES driven by the two GCMs, HadGEM2-A and CNRM-CM5, at sites 17 and 23 in July. At 

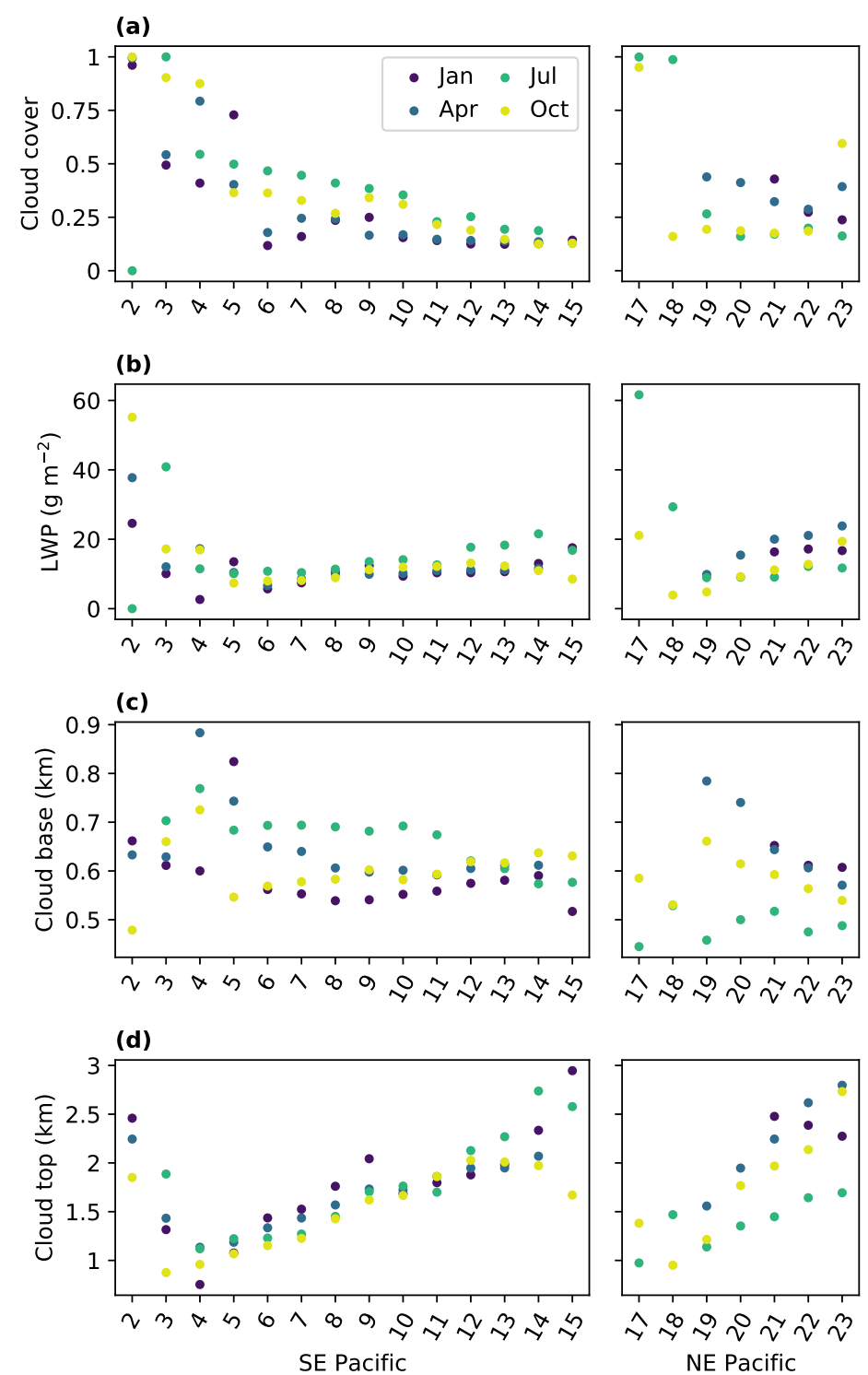

Figure 2: (a) Cloud cover, (b) cloud liquid water path (LWP), (c) cloud base height, and (d) cloud top height at different sites in the LES driven by HadGEM2-A in different seasons. Missing points indicate the cloud top height is higher than $3000 \mathrm{~m}$. 


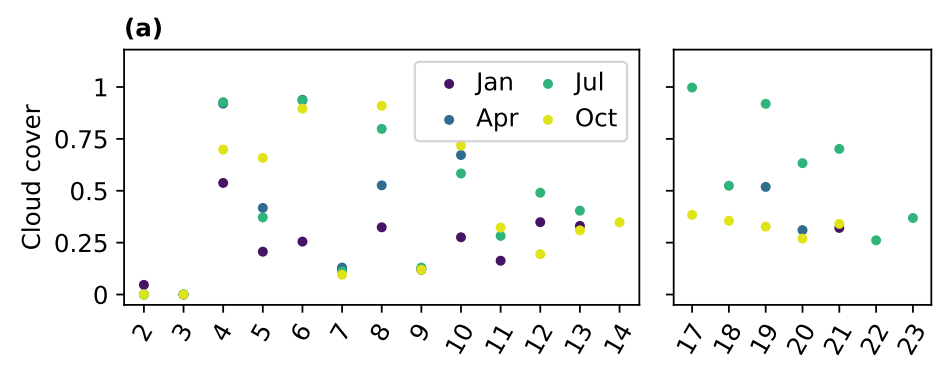

(b)
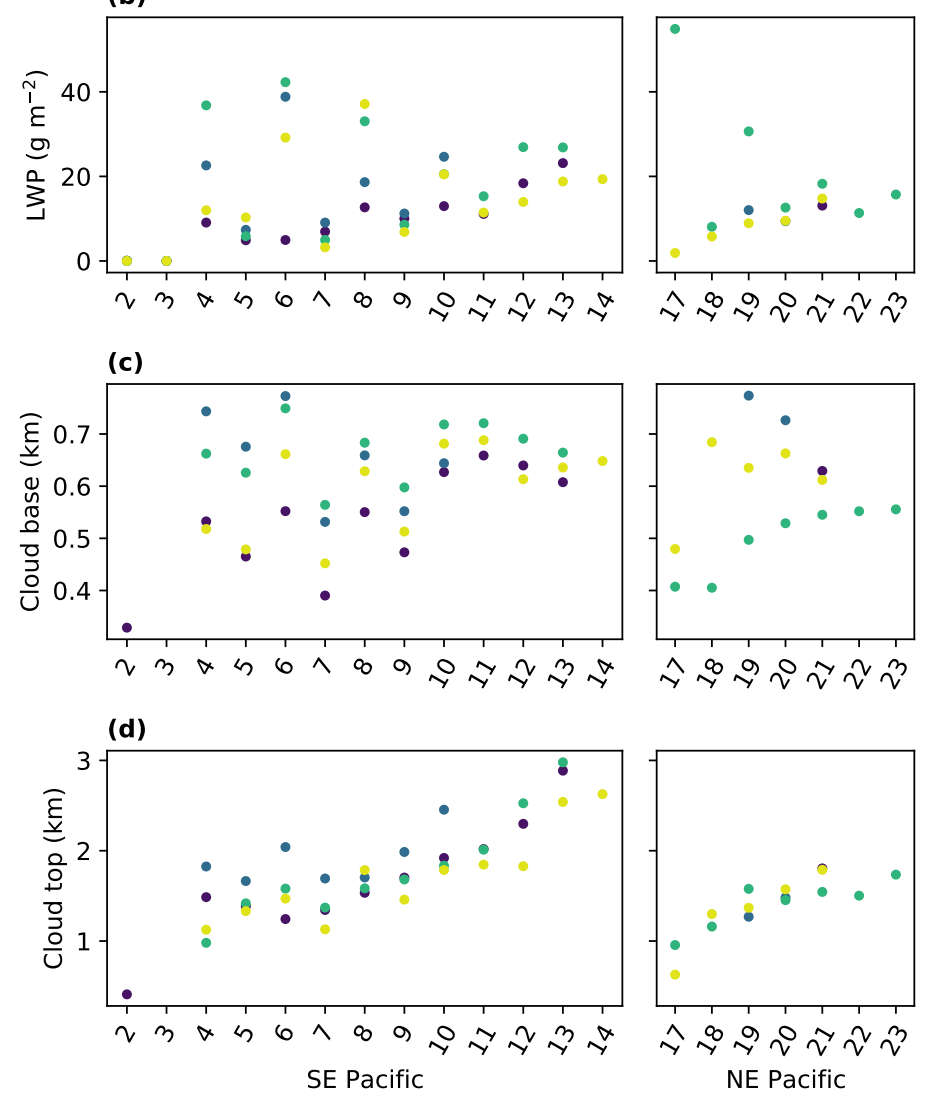

Figure 3: Same as Figure 2 but for LES driven by CNRM-CM5. 

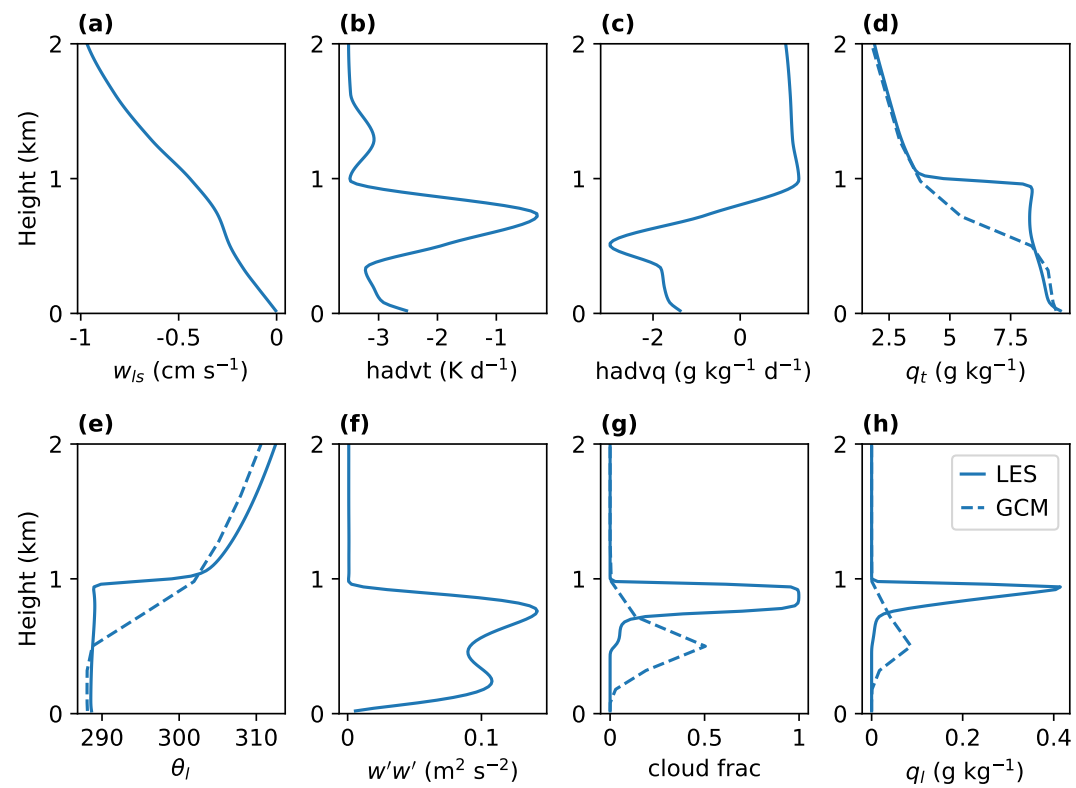

Figure 4: Vertical profiles of (a) large-scale vertical velocity, (b) horizontal advection of temperature, (c) horizontal advection of specific humidity, (d) total water specific humidity, (e) liquid potential temperature, (f) vertical velocity variance, (g) cloud fraction, and (h) cloud liquid water specific humidity in the LES driven by HadGEM2-A at site 17 in July. The dashed lines represent the GCM profiles.
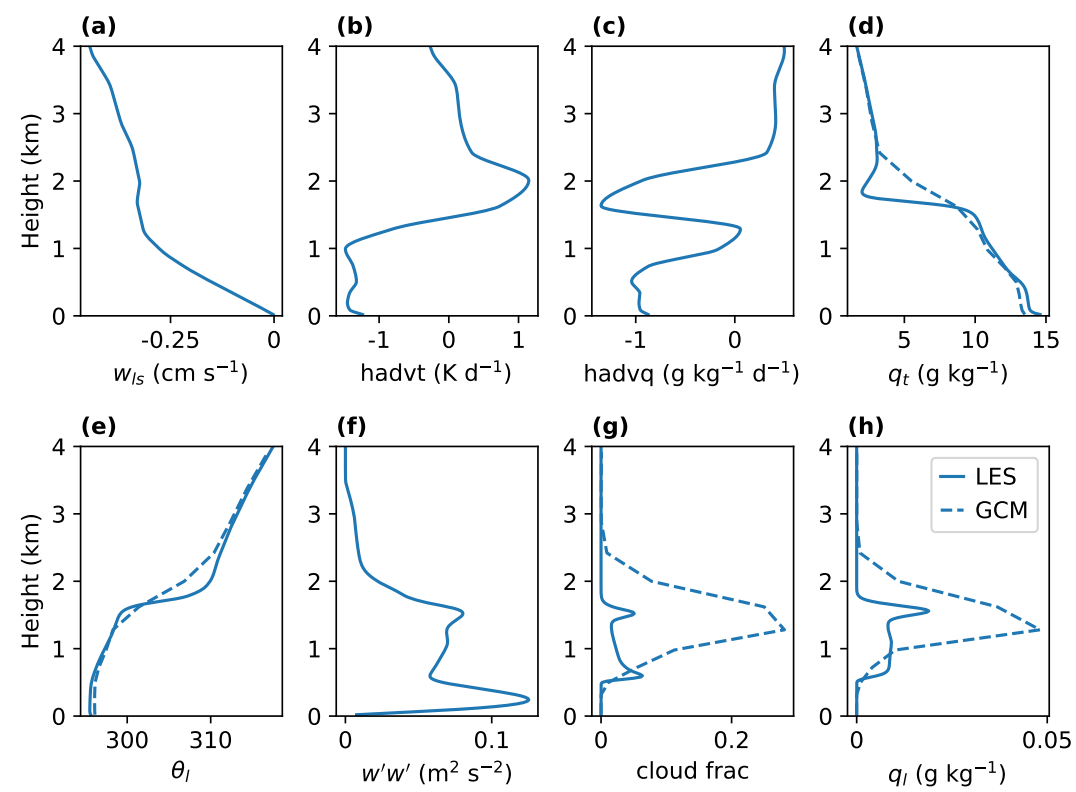

Figure 5: Same as Figure 4, but for site 23 in July. 
(a)

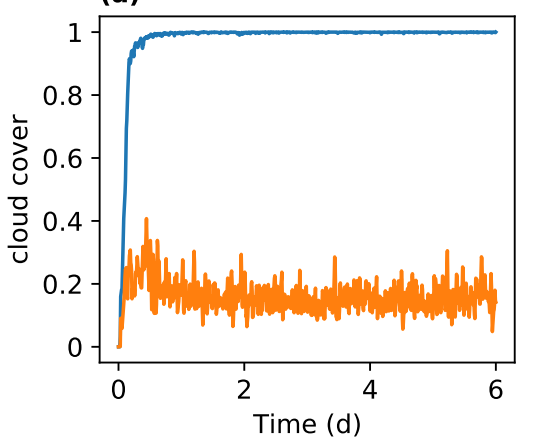

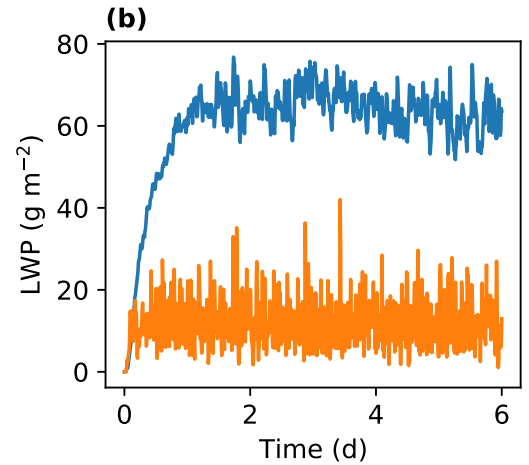

Figure 6: Time series of (a) cloud cover and (b) liquid water path in the LES driven by HadGEM2-A. Blue and orange lines represent sites 17 and 23 in July, respectively.

(a)

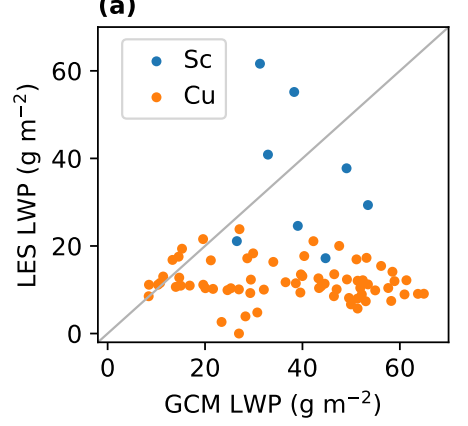

(b)

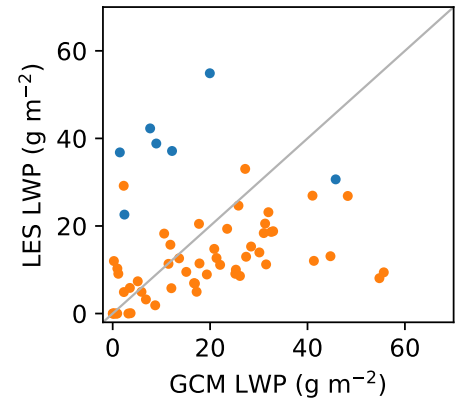

Figure 7: Scatter plot of LWP in the LES and GCM at different sites. Blue and orange dots represent stratocumulus $(\mathrm{Sc})$ and shallow cumulus $(\mathrm{Cu})$ in the LES, respectively. The host GCMs are (a) HadGEM2-A and (b) CNRM-CM5. 


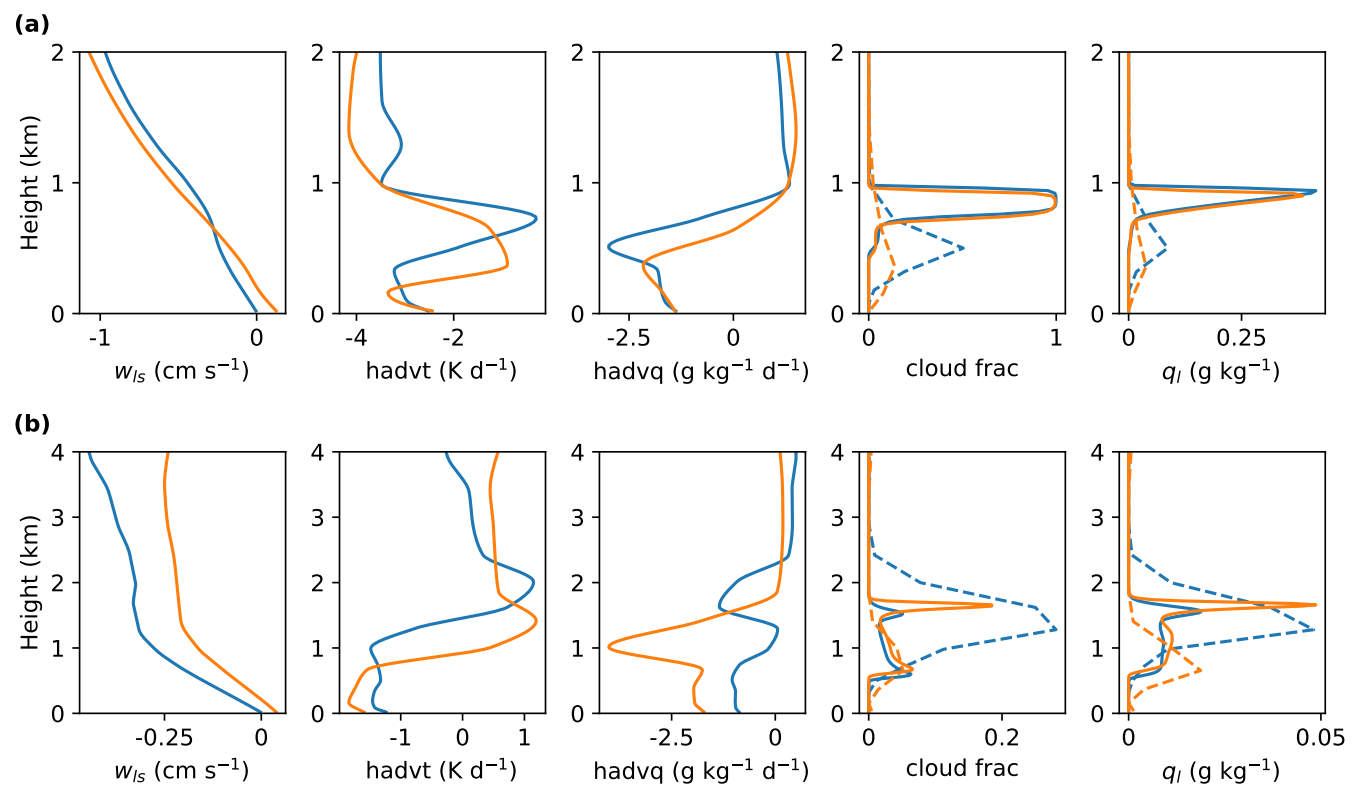

Figure 8: Vertical profiles of large-scale vertical velocity, horizontal advection of temperature, horizontal advection of specific humidity, cloud fraction, and cloud liquid water specific humidity for (a) site 17 and (b) site 23 in July. Blue and orange lines represent LES driven by the large-scale forcing from HadGEM2-A and CNRM-CM5, respectively. Dashed lines represent the host GCMs.

(a)

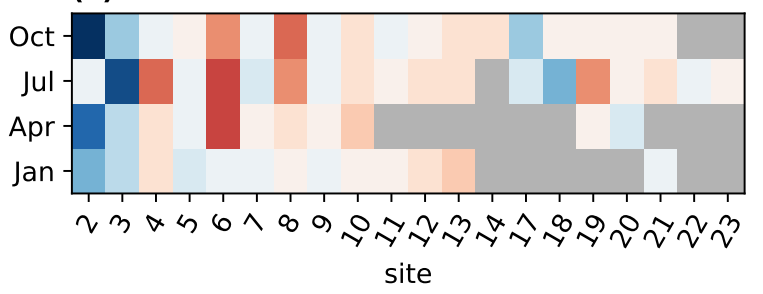

(b)

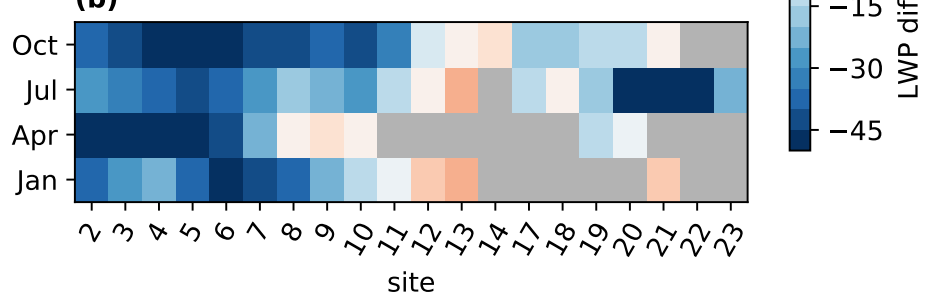

Figure 9: LWP differences at different sites between (a) LES driven by large-scale forcing from HadGEM2-A and CNRM-CM5 and (b) HadGEM2-A and CNRM-CM5. The differences are shown as CNRM-CM5 minus HadGEM2-A. Gray colors indicate the cloud top in at least one of the LES simulations is higher than $3000 \mathrm{~m}$. In the GCMs, LWP is calculated as the vertical integral of cloud liquid water from the surface to $3000 \mathrm{~m}$. 


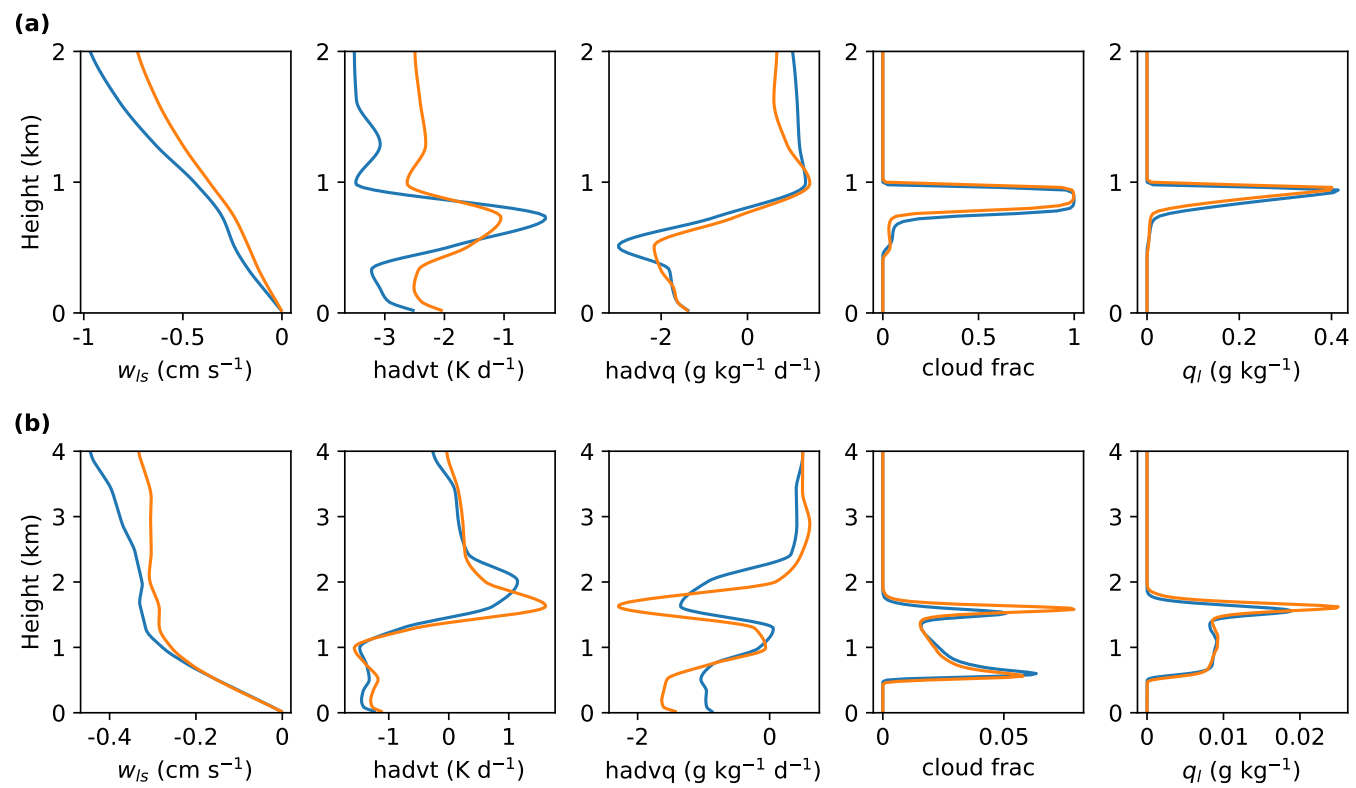

Figure 10: Vertical profiles of large-scale vertical velocity, horizontal advection of temperature, horizontal advection of specific humidity, cloud fraction, and cloud liquid water specific humidity for (a) site 17 and (b) site 23 in July. Blue and orange lines represent LES driven by the large-scale forcing from the AMIP and AMIP4K experiments in HadGEM2-A, respectively.

The LES library, including LES of changed climates, provides an opportunity to systematically train GCM parameterizations. Although the LES may not correctly reproduce clouds in response to time-varying large-scale forcings, the objective is to expand the dataset available for calibrating single column models. To this end, the LES results should be compared with single-column models driven by the same time-mean large-scale forcings, and ideally with the same parameterizations for other physical processes such as radiation and microphysics. The convective parameterization schemes can be calibrated by minimizing mismatches between the LES and single-column models, for example, with Bayesian methods (Cleary et al., 2021). The experimental design allows an iterative workflow, where GCM parameterizations can learn from LES results, and LES can be run with new large-scale forcings from the GCM with improved parameterizations. While this study focused on low clouds over the East Pacific, driving LES with large-scale forcings from GCMs can be done anywhere on the globe. Optimal experimental design approaches can be used to select the locations to generate LES that are most informative about parameterizations (Schneider, Lan, et al., 2017).

The LES of changed climates can also be used to investigate mechanisms of cloud feedbacks under realistic changes in large-scale forcings. This will be explored in more detail in future work. 


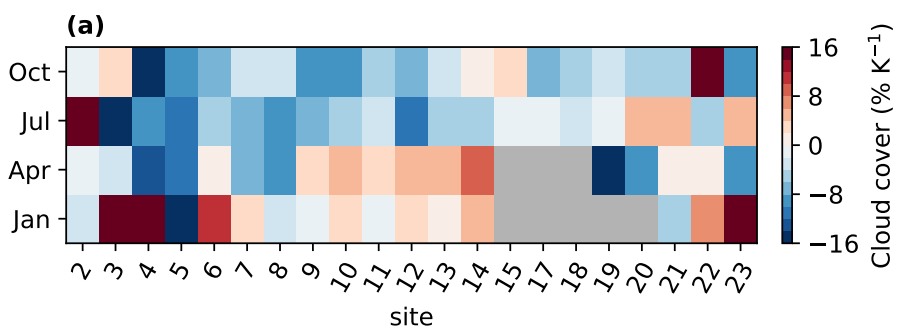

(b)
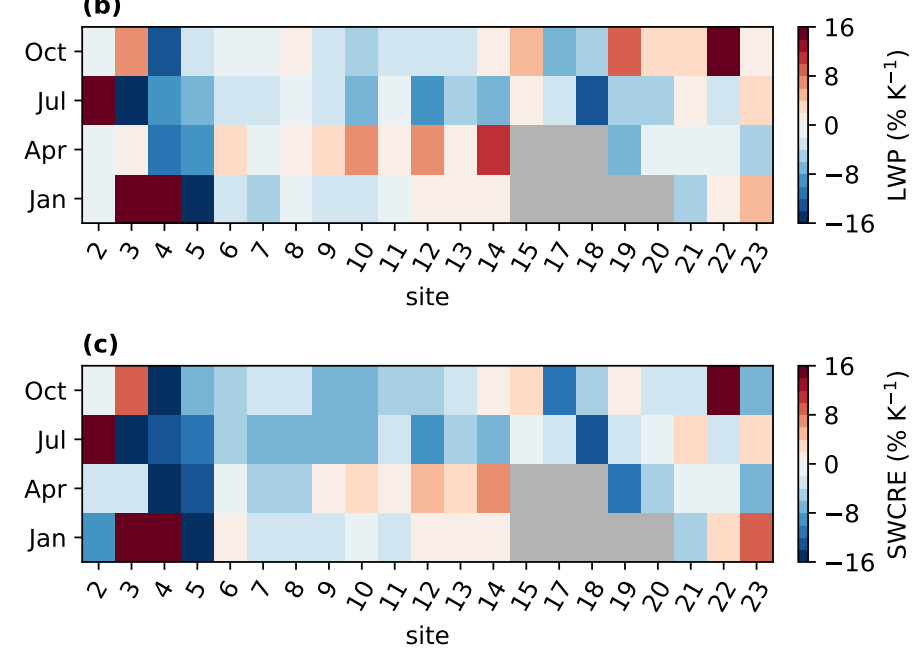

Figure 11: Percentage changes in (a) cloud cover, (b) LWP, and (c) shortwave cloud radiative effect resulting from a $4 \mathrm{~K}$ increase in SST in the LES driven by HadGEM2-A. Gray colors indicate the cloud top in the LES in the current or warmer climate is higher than $3000 \mathrm{~m}$. 

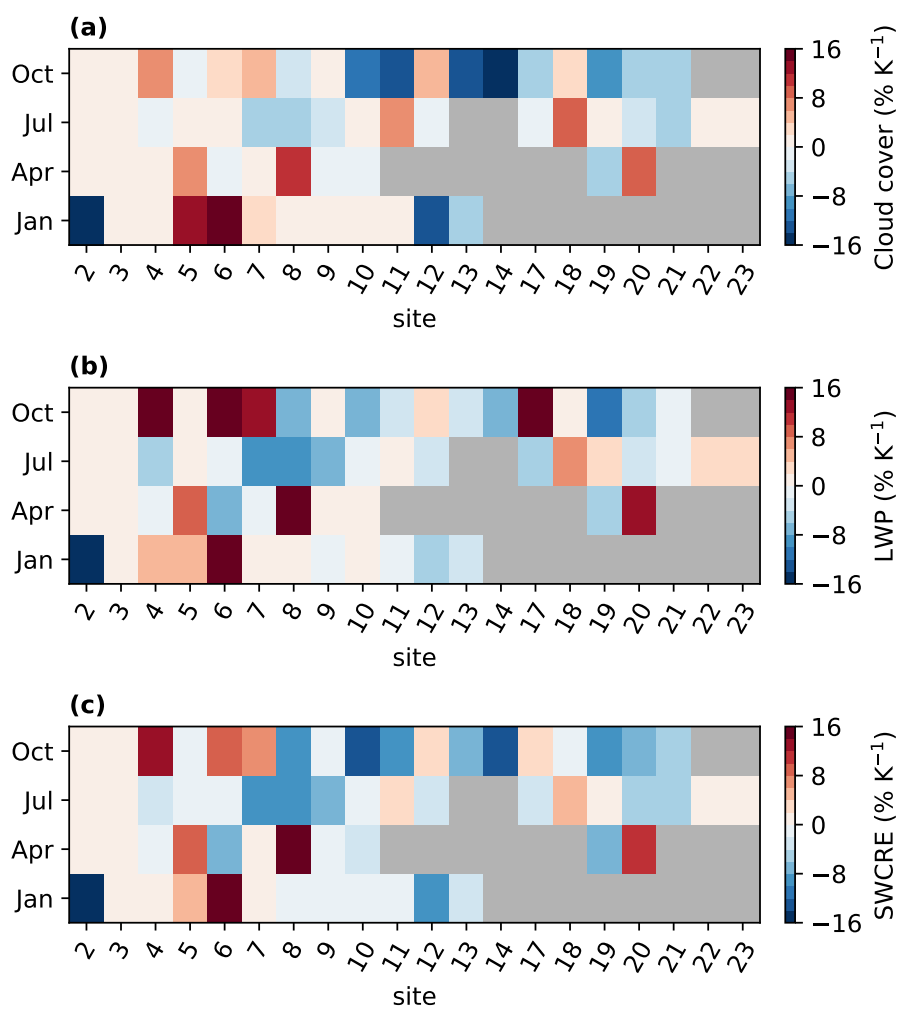

Figure 12: Same as Figure 11 but for LES driven by CNRM-CM5.
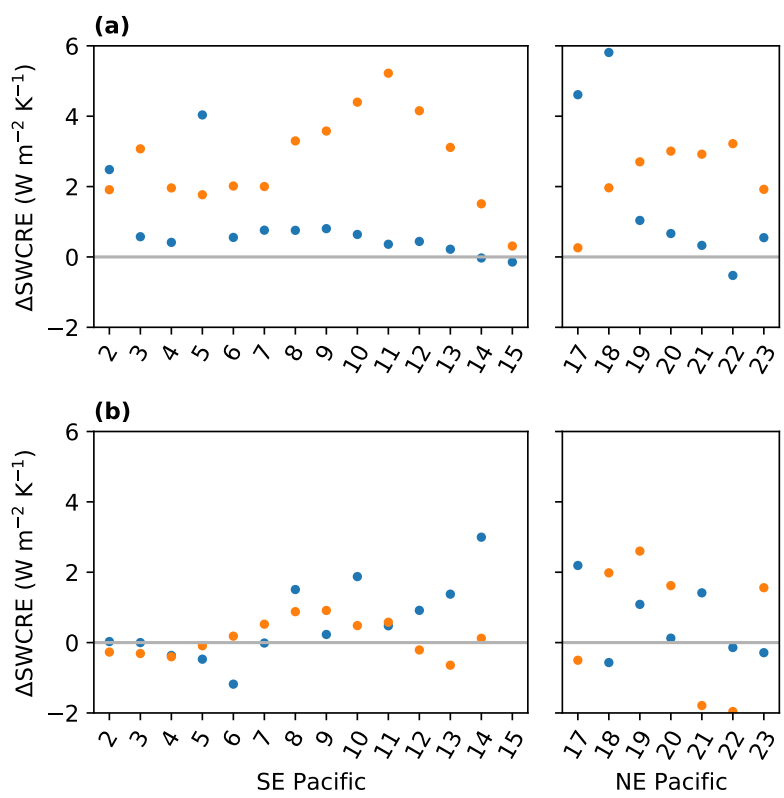

Figure 13: LES (blue) and GCM (orange) simulated shortwave cloud feedback under a $4 \mathrm{~K}$ increase in SST. The host GCMs are (a) HadGEM2-A and (b) CNRM-CM5. The results are averaged over all seasons. 


\section{Acknowledgments}

We thank Yassine Tissaoui and Simone Marras for helpful discussion. We gratefully acknowledge the generous support of Eric and Wendy Schmidt (by recommendation of Schmidt Futures), Charles Trimble, the Paul G. Allen Family Foundation, and the National Science Foundation (Grant 1835860). The simulations were performed on Caltech's High Performance Cluster, which is partially supported by a grant from the Gordon and Betty Moore Foundation. Part of this research was carried out at the Jet Propulsion Laboratory, California Institute of Technology, under a contract with the National Aeronautics and Space Administration. CMIP5 data can be accessed at https://esgf-node.1lnl .gov/projects/cmip5/. The LES codes are available on the GitHub repository https:// github.com/szy21/pycles_GCM/releases/tag/v1.0. The LES library will be made publicly available upon acceptance of this paper.

\section{References}

Blossey, P. N., Bretherton, C. S., Cheng, A., Endo, S., Heus, T., Lock, A. P., \& van der Dussen, J. J. (2016). Cgils p hase 2 les intercomparison of response of subtropical marine low cloud regimes to co 2 quadrupling and a cmip 3 composite forcing change. Journal of Advances in Modeling Earth Systems, 8(4), 1714-1726.

Blossey, P. N., Bretherton, C. S., Zhang, M., Cheng, A., Endo, S., Heus, T., ... Xu, K.-M. (2013). Marine low cloud sensitivity to an idealized climate change: The cgils les intercomparison. Journal of Advances in Modeling Earth Systems, $5(2), 234-258$.

Bony, S., Colman, R., Kattsov, V. M., Allan, R. P., Bretherton, C. S., Dufresne, J.L., ... others (2006). How well do we understand and evaluate climate change feedback processes? Journal of Climate, 19(15), 3445-3482.

Bony, S., \& Dufresne, J.-L. (2005). Marine boundary layer clouds at the heart of tropical cloud feedback uncertainties in climate models. Geophysical Research Letters, 32(20).

Bony, S., Webb, M., Bretherton, C., Klein, S., Siebesma, P., Tselioudis, G., \& Zhang, M. (2011). Cfmip: Towards a better evaluation and understanding of clouds and cloud feedbacks in cmip5 models.

Bretherton, C. S. (2015). Insights into low-latitude cloud feedbacks from highresolution models. Philosophical Transactions of the Royal Society A: Mathematical, Physical and Engineering Sciences, 373(2054), 20140415.

Bretherton, C. S., \& Blossey, P. N. (2014). Low cloud reduction in a greenhousewarmed climate: Results from lagrangian les of a subtropical marine cloudiness transition. Journal of Advances in Modeling Earth Systems, 6(1), 91-114.

Bretherton, C. S., Blossey, P. N., \& Jones, C. R. (2013). Mechanisms of marine low cloud sensitivity to idealized climate perturbations: A single-les exploration extending the cgils cases. Journal of Advances in Modeling Earth Systems, $5(2), 316-337$.

Brient, F., Roehrig, R., \& Voldoire, A. (2019). Evaluating marine stratocumulus clouds in the cnrm-cm6-1 model using short-term hindcasts. Journal of Advances in Modeling Earth Systems, 11(1), 127-148.

Brient, F., \& Schneider, T. (2016). Constraints on climate sensitivity from spacebased measurements of low-cloud reflection. Journal of Climate, 29(16), 58215835 .

Byun, D. W. (1990). On the analytical solutions of flux-profile relationships for the atmospheric surface layer. Journal of Applied Meteorology (1988-2005), 652657.

Cesana, G., \& Del Genio, A. D. (2021). Observational constraint on cloud feedbacks suggests moderate climate sensitivity. Nature Climate Change, 11(3), $213-218$. 
Cesana, G., \& Waliser, D. (2016). Characterizing and understanding systematic biases in the vertical structure of clouds in cmip5/cfmip2 models. Geophysical Research Letters, 43(19), 10-538.

Cleary, E., Garbuno-Inigo, A., Lan, S., Schneider, T., \& Stuart, A. M. (2021). Calibrate, emulate, sample. Journal of Computational Physics, 424, 109716.

Iacono, M. J., Delamere, J. S., Mlawer, E. J., Shephard, M. W., Clough, S. A., \& Collins, W. D. (2008). Radiative forcing by long-lived greenhouse gases: Calculations with the aer radiative transfer models. Journal of Geophysical Research: Atmospheres, $113(\mathrm{D} 13)$.

Kessler, E. (1995). On the continuity and distribution of water substance in atmospheric circulations. Atmospheric research, 38(1-4), 109-145.

Klein, S. A., Zhang, Y., Zelinka, M. D., Pincus, R., Boyle, J., \& Gleckler, P. J. (2013). Are climate model simulations of clouds improving? an evaluation using the isccp simulator. Journal of Geophysical Research: Atmospheres, $118(3), 1329-1342$.

Lilly, D. K. (1962). On the numerical simulation of buoyant convection. Tellus, $14(2), 148-172$.

Myers, T. A., Scott, R. C., Zelinka, M. D., Klein, S. A., Norris, J. R., \& Caldwell, P. M. (2021). Observational constraints on low cloud feedback reduce uncertainty of climate sensitivity. Nature Climate Change, 1-7.

Nam, C., Bony, S., Dufresne, J.-L., \& Chepfer, H. (2012). The 'too few, too bright'tropical low-cloud problem in cmip5 models. Geophysical Research Letters, 39(21).

Neggers, R. A., Siebesma, A., \& Heus, T. (2012). Continuous single-column model evaluation at a permanent meteorological supersite. Bulletin of the American Meteorological Society, 93(9), 1389-1400.

Nuijens, L., \& Siebesma, A. P. (2019). Boundary layer clouds and convection over subtropical oceans in our current and in a warmer climate. Current Climate Change Reports, 5(2), 80-94.

O'Gorman, P. A., \& Dwyer, J. G. (2018). Using machine learning to parameterize moist convection: Potential for modeling of climate, climate change, and extreme events. Journal of Advances in Modeling Earth Systems, 10(10), $2548-2563$.

Pressel, K. G., Kaul, C. M., Schneider, T., Tan, Z., \& Mishra, S. (2015). Large-eddy simulation in an anelastic framework with closed water and entropy balances. Journal of Advances in Modeling Earth Systems, 7(3), 1425-1456.

Pressel, K. G., Mishra, S., Schneider, T., Kaul, C. M., \& Tan, Z. (2017). Numerics and subgrid-scale modeling in large eddy simulations of stratocumulus clouds. Journal of advances in modeling earth systems, 9(2), 1342-1365.

Radtke, J., Mauritsen, T., \& Hohenegger, C. (2021). Shallow cumulus cloud feedback in large eddy simulations-bridging the gap to storm-resolving models. Atmospheric Chemistry and Physics, 21(5), 3275-3288.

Randall, D. A., \& Cripe, D. G. (1999). Alternative methods for specification of observed forcing in single-column models and cloud system models. Journal of Geophysical Research: Atmospheres, 104(D20), 24527-24545.

Rauber, R. M., Stevens, B., Ochs III, H. T., Knight, C., Albrecht, B., Blyth, A., ... others (2007). Rain in shallow cumulus over the ocean: The rico campaign. Bulletin of the American Meteorological Society, 88(12), 1912-1928.

Schneider, T., Lan, S., Stuart, A., \& Teixeira, J. (2017). Earth system modeling 2.0: A blueprint for models that learn from observations and targeted highresolution simulations. Geophysical Research Letters, 44(24), 12-396.

Schneider, T., Teixeira, J., Bretherton, C. S., Brient, F., Pressel, K. G., Schär, C., \& Siebesma, A. P. (2017). Climate goals and computing the future of clouds. Nature Climate Change, 7(1), 3-5.

Shen, Z., Pressel, K. G., Tan, Z., \& Schneider, T. (2020). Statistically steady state 
large-eddy simulations forced by an idealized gcm: 1 . forcing framework and simulation characteristics. Journal of Advances in Modeling Earth Systems, 12(2), e2019MS001814.

Shu, C.-W., \& Osher, S. (1988). Efficient implementation of essentially nonoscillatory shock-capturing schemes. Journal of computational physics, $77(2)$, 439-471.

Siebesma, A. P., Bretherton, C. S., Brown, A., Chlond, A., Cuxart, J., Duynkerke, P. G., ... others (2003). A large eddy simulation intercomparison study of shallow cumulus convection. Journal of the Atmospheric Sciences, 60(10), $1201-1219$.

Smagorinsky, J. (1963). General circulation experiments with the primitive equations: I. the basic experiment. Monthly weather review, 91(3), 99-164.

Stevens, B., Moeng, C.-H., Ackerman, A. S., Bretherton, C. S., Chlond, A., de Roode, S., ... others (2005). Evaluation of large-eddy simulations via observations of nocturnal marine stratocumulus. Monthly weather review, 133(6), 1443-1462.

Tan, Z., Schneider, T., Teixeira, J., \& Pressel, K. G. ～(2016). Large-eddy simulation of subtropical cloud-topped boundary layers: 1. a forcing framework with closed surface energy balance. Journal of Advances in Modeling Earth Systems, 8(4), 1565-1585.

Tan, Z., Schneider, T., Teixeira, J., \& Pressel, K. G. ～(2017). Large-eddy simulation of subtropical cloud-topped boundary layers: 2. cloud response to climate change. Journal of Advances in Modeling Earth Systems, 9(1), 19-38.

Vignesh, P. P., Jiang, J. H., Kishore, P., Su, H., Smay, T., Brighton, N., \& Velicogna, I. (2020). Assessment of cmip6 cloud fraction and comparison with satellite observations. Earth and Space Science, 7(2), e2019EA000975.

Zelinka, M. D., Myers, T. A., McCoy, D. T., Po-Chedley, S., Caldwell, P. M., Ceppi, P., ... Taylor, K. E. (2020). Causes of higher climate sensitivity in cmip6 models. Geophysical Research Letters, 47(1), e2019GL085782.

Zhang, M., Bretherton, C. S., Blossey, P. N., Austin, P. H., Bacmeister, J. T., Bony, S., ... others (2013). Cgils: Results from the first phase of an international project to understand the physical mechanisms of low cloud feedbacks in single column models. Journal of Advances in Modeling Earth Systems, 5(4), 826-842.

Zhang, M., Bretherton, C. S., Blossey, P. N., Bony, S., Brient, F., \& Golaz, J.-C. (2012). The cgils experimental design to investigate low cloud feedbacks in general circulation models by using single-column and large-eddy simulation models. Journal of Advances in Modeling Earth Systems, 4(4). 